\title{
CONTENÇÃO MECÂNICA DE ANIMAIS: REVISÃO BIBLIOGRÁFICA
}

\author{
Gil Dutra FURTADO ${ }^{1 *}$; Felipe Eduardo da Silva SOBRAL ${ }^{2}$
}

\author{
${ }^{1}$ Graduando em Medicina Veterinária/Centro Universitário Maurício de Nassau (UNINASSAU-PB), João Pessoa, \\ Paraíba; Agrônomo/Universidade Federal da Paraíba (UFPB); Doutor em Psicobiologia/Universidade Federal do \\ Rio Grande do Norte (UFRN); Agrônomo-Sócio da Cooperativa do Agronegócio (COOPAGRO), Natal, Rio \\ Grande do Norte, Brasil. \\ ${ }^{2}$ Mestre; Médico Veterinário; Professor/UNINASSAU-PB, João Pessoa, Paraíba, Brasil. \\ *Endereço para contato: E-mail: gdfurtado@ hotmail.com
}

Resumo. O objetivo desta pesquisa trata-se de explanar sobre a contenção mecânica, principalmente, que é restringir da maneira mais eficiente possível, a atividade física de um animal, na intenção de realizar avaliações e procedimentos do paciente, tais como curativos, ações medicamentosas, dentre outros. Este é necessário pois por mais manso que seja o paciente, a simples palpação de uma determinada estrutura que possua um aumento de sensibilidade fará com que ele se defenda com mordeduras, coices, chifradas e/ou unhadas. Sob esta realidade, com base em nove fontes de informações científicas pesquisadas, observa-se que se torna importante que o animal esteja adequadamente contido. Este proporcionará maior segurança para o médico veterinário, auxiliar e para o próprio animal, além de propiciar um procedimento mais satisfatório.

Palavras-chave: Medicina Veterinária; Contenção; Segurança.

\section{MECHANICAL CONTAINMENT OF ANIMALS: LITERATURE REVIEW}

Abstract. The objective of this research is to explain about mechanical restraint, mainly, which is to restrict in the most efficient way possible, the physical activity of an animal, with the intention of carrying out evaluations and procedures of the patient, such as dressings, medication actions, among others. This is necessary because, however gentle the patient may be, the simple palpation of a given structure that has an increase in sensitivity will cause him to defend himself with bites, kicks, horns and / or nails. Under this reality, based on nine sources of researched scientific information, it is observed that it is important that the animal is adequately contained. This will provide greater security for the veterinarian, assistant and the animal itself, in addition to providing a more satisfactory procedure.

Keywords: Veterinary Medicine; Containment; Safety.

\section{CONTENCIÓN MECÁNICA DE ANIMALES: REVISIÓN DE LITERATURA}

Resumen. El objetivo de esta investigación es explicar sobre la contención mecánica, principalmente, que consiste en restringir de la forma más eficiente posible, la actividad física de un animal, con la 
intención de realizar evaluaciones y procedimientos del paciente, como apósitos, medicación acciones, entre otras. Esto es necesario porque, por suave que sea el paciente, la simple palpación de una determinada estructura que tiene un aumento de sensibilidad hará que se defienda con mordiscos, patadas, cuernos y / o uñas. Bajo esta realidad, a partir de nueve fuentes de información científica investigada, se observa que es importante que el animal esté adecuadamente contenido. Esto brindará una mayor seguridad para el veterinario, asistente y el propio animal, además de brindar un procedimiento más satisfactorio.

Palabras llave: Medicina veterinaria; Contención; Seguridad.

\section{INTRODUÇÃO}

A contenção mecânica ou farmacológica de animais (rurais, silvestres ou PET) podem ser empregadas para diversos fins e situações. A contenção de um animal pode ir deste a limitação de seus movimentos podendo ir até mesmo a sua completa imobilização. O ser humano vem procurando adaptar os métodos de contenção objetivando facilitar o manejo com os animais bem como manter a segurança na lida com os mesmos. Tendo estas primícias em destaque, ao manusear com os animais rurais, PET ou silvestres, sempre se deve procurar reduzir as possibilidades de acidentes, aprimorando e utilizando métodos de contenção que sejam seguros (ANDRADE; CORREIA PINTO; OLIVEIRA, 2002; SILVA et al., 2012).

A contenção dos animais objetiva a imobilização para executar procedimentos de aplicação medicamentosa, realizar curativos, coletar material biológico para exames, dentre outros. Esta ação deve proporcionar proteção para o atendimento, mantendo o animal imobilizado e viabilizar toda a manipulação necessária com o animal (MARTINS, 2019).

Não se deve ignorar que por mais calmo o animal esteja, ambientes diferentes como as clínicas são hostis para eles. Sempre é recomendado realizar a contenção, independente do temperamento dos animais, pois até o animal mais calmo pode agir agressivamente como reflexo a dor ou algum incômodo, gerando acidentes. A simples realização de uma palpação, em uma área de sensibilidade ampliada pela dor, pode desencadear uma reação de defesa do animal, culminando em mordidas, arranhões ou em um acidente mais sério (MARTINS, 2019).

Para que os procedimentos clínicos sejam realizados de maneira satisfatória, garantindo segurança e tranquilidade, a contenção de animais precisa ser feita de forma correta, onde os principais objetivos deverão ser o possibilitar a realização de diversas manobras como: exames de radiologia, coleta de sangue, aplicação medicamentosa, dentre outros; evitar que o animal fuja e venha a sofrer algum acidente como fraturas; proteger o médico veterinário, o auxiliar e 
os demais envolvidos; proporcionar segurança e facilitar o exame clínico (ANDRADE; CORREIA PINTO; OLIVEIRA, 2002; SILVA et al., 2012).

Deve-se procurar, primariamente, viabilizar a socialização com o animal, favorecendo uma abordagem que seja mais assertiva, pois do contrário, a abordagem errada pode desencadear comportamentos agressivos, e prejudicar o diagnóstico. Também deve-se proporcionar um ambiente tranquilo, sendo importante ter atenção na iluminação, evitar o trânsito de pessoas e a ocorrência de barulhos desnecessários. Estes detalhes tendem a facilitar a manipulação do animal e proporcionam um melhor desenvolvimento da ação (MARTINS, 2019).

A contenção deve ser feita de forma segura, não ser cruel e nem causar dores e prejuízos ao paciente. A contenção física visa facilitar a realização dos exames e procedimentos, evitando movimentos bruscos e precipitados. Neste artigo objetiva-se apresentar algumas técnicas utilizadas para realizar a contenção de animais de forma a proteger os profissionais bem como viabilizar a segurança e bem-estar dos pacientes.

\section{MATERIAL E MÉTODOS}

Realizou-se análise documental objetivando à identificação de temas representativos quanto a temática desta pesquisa acadêmica. Os dados foram levantados por meio da análise exploratória de conteúdos científicos, oriundos de nove materiais de pesquisa pré-selecionados. Todo o material estudado envolveu compêndios científicos, periódicos, anais, livros, dentre outros, sendo todos de origem on-line (BARDIN, 1977; DIAS et al., 2011; GIL, 2011).

\section{RESULTADOS}

A contenção dos animais pode ser entendida como uma metodologia de evitar agressão do animal ao manipulador do mesmo, na hora da ação do médico veterinário. Envolve ações de técnicas onde o profissional deve ter pleno conhecimento para a sua aplicação satisfatória, atingindo eficientemente o objetivo proposto.

Dentre as muitas técnicas de contenção, algumas delas podem ser:

\section{Cães}

Contenção manual:

Coloque um braço sob o pescoço e passe o outro braço sob o abdome do animal (ANDRADE; CORREIA PINTO; OLIVEIRA, 2002; MARTINS, 2019). 
Focinheira ou mordaça:

Existem modelos para cães e gatos. $\mathrm{O}$ modelo para gatos cobre toda a face, inclusive olhos. Isso ajuda a acalmar o animal estressado. As focinheiras de nylon são maleáveis e não machucam. Há modelos em plástico rígido também (ANDRADE; CORREIA PINTO; OLIVEIRA, 2002; MARTINS, 2019).

Obs.:

Os laços devem seguir uma ordem lógica, sendo o primeiro laço em cima do focinho, o segundo embaixo e o terceiro atrás da orelha.

Cambão:

O cambão é uma haste rígida com um laço na ponta. É muito usado para a captura de animais que não permitem a aproximação. Pode ser improvisado com um pedaço de madeira com uma argola na ponta e uma corda (ANDRADE; CORREIA PINTO; OLIVEIRA, 2002; MARTINS, 2019).

Coleira e guia:

A coleira e a guia são utilizados para a condução dos animais, sendo compostas de uma tira de couro ou corrente e tem um fixador na coleira, que também pode ser de couro ou metal e fica ao redor do pescoço do animal e que em certos casos podem ser também utilizados para apoio na contenção destes. Utilizando a guia, passa-se esta pela grade de um portão ou se for mais prático para a ocasião, enrolando-a à um poste (ou perna de mesa), proceda assim:

Posicione o pescoço do cão bem encostado ao anteparo para que a cabeça fique segura e estando firme, com a cabeça bem imobilizada, uma segunda pessoa deve segurar firmemente as patas traseiras do cão, imobilizando-o (FEITOSA, 2014; MARTINS, 2019).

\section{Colar Elizabetano:}

Este é um instrumento utilizado no pós-operatório veterinário e serve para restringir os movimentos do animal, vindo com este, impedir que o processo de recuperação seja afetado. Este colar é ligado a coleira do animal, de forma fixa e eficiente, passados através de orifícios localizados nas laterais do colar. O colar elizabetano é usado para impedir que o cão (ou o gato) retire curativos ou arranque suturas. Este não restringe os movimentos, evitará que alcance 
alguma parte de seu corpo com a boca, porem poderá comer, beber e dormir sem impedimento (FEITOSA, 2014; MARTINS, 2019).

\section{Gatos}

Gatos muito agressivos ou assustados podem ser segurados pela pele que reveste a porção superior da região cervical, logo atrás das orelhas, o que o impedirá de virar a cabeça e morder a pessoa que realiza a contenção. Outra opção seria a junção de ambos os pavilhões auriculares, com os dedos polegar e indicador de uma das mãos. Essa manobra deixa-os imóveis, em virtude da grande sensibilidade que essas estruturas apresentam quando são fortemente comprimidas (FEITOSA, 2014; MARTINS, 2019).

\section{Bovinos}

Os métodos empregados para conter e derrubar bovinos diferem segundo o sexo, idade, raça, temperamento e o local no corpo do animal onde se pretende trabalhar.

Em relação às fêmeas de bovinos, deve-se fazer a aproximação pelo lado direito, por onde são ordenhadas. Ao contrário dos equinos, os bovinos atacam com as extremidades anteriores em sentido lateral, descrevendo, com elas, um semicírculo com movimento para trás (MARTINS, 2019; SENAR, 2017).

A contenção de bovinos, principalmente os mais arredios, pode iniciar-se pela amarração da cabeça por meio de laços, focinheiras e cabrestos ou prendendo-a em guilhotinas de bretes de contenção. Em seguida, sugere-se aplicar um guia nasal (formiga nasal) associando a elevação da cauda (FEITOSA, 2014; MARTINS, 2019).

Tronco:

O tronco de retenção é utilizado na contenção dos bovinos indóceis, que para este manejo, deve-se juntar o animal a outros bovinos (manejo denominado de "amadrinhamento") e, durante a passagem deste rebanho por um brete de contenção (equipamento projetado para conter e imobilizar bovinos, individualmente, objetivando facilitar os tratos veterinários de manejo), prendê-lo no tronco de contenção quando estiver posicionado entre ele (MARTINS, 2019; SENAR, 2017).

Método de Rueff:

Com uma corda de 12 metros, procede-se em realizar uma laçada na base do chifre ou no pescoço do animal, seguido de mais duas laçadas iguais, sendo uma pelo tórax e a outra pelo 
flanco do animal. Estas laçadas precisam ficar posicionadas na metade do corpo do animal (antímero), podendo ser o esquerdo ou direito. Estando pronto este manejo com a corda, dois ou três ajudantes tracionarão a extremidade da corda para trás, o que culminará na queda do animal (MARTINS, 2019; SENAR, 2017).

\section{Método Italiano:}

Neste método, passasse a metade de uma corda de tamanho adequado ao animal, pelo pescoço e na frente da cernelha. Prossegue-se cruzando as extremidades desta corda por baixo do pescoço e volta a corda sobre a região torácica, levando as pontas da corda por entre os membros posteriores. Estando pronto este, cada extremidade livre da corda é tracionada por um auxiliar, tendo o cuidado de ter um terceiro auxiliar segura a cabeça do animal, até a queda deste (MARTINS, 2019; SENAR, 2017).

\section{Equinos}

Alguns animais que possuem orelhas de maior tamanho, podem ser contidos com uma apreensão, seguida de compressão. Inicialmente o animal poderá resistir, porem depois de algumas tentativas de resistência, em geral, permitem a manipulação. Os animais que sejam mais arredios, podem ser contidos por meios como o cachimbo, mão de amigo e pé de amigo, travões e método antigo (MARTINS, 2019).

\section{Cachimbo:}

O cachimbo é um instrumento muito eficiente, onde a sua colocação no lábio (nferior ou superior) com a realização de uma torção, induzirá o animal a sentir uma dor considerável, que o obrigará a manter quieto (MARTINS, 2019).

Mão de amigo e/ou pé de amigo:

Neste método de imobilização procura-se suspender um dos membros, anterior (mão de amigo) ou posterior (pé de amigo), tirando o apoio do animal e induzindo-o a ficar contido (MARTINS, 2019).

Para proceder com a derrubada de um equino, pode-se utilizar caneleiras e/ou cordas. Os métodos mais comumente utilizados são:

Método dos travões: 
Neste método, utiliza-se travões, argolas, um conjunto de quatro correias de tamanho de largura uniforme e geralmente de couro cru, grossas e resistentes. Em uma das extremidades coloca-se uma forte fivela fixa que prende a caneleira no membro. A também tem o objetivo de unir as caneleiras, provocando o desequilíbrio do animal. Esta corda precisa ser resistente, e ter aproximadamente dez metros (FEITOSA, 2014; MARTINS, 2019).

\section{Método Antigo:}

Este método é um processo de derrubamento de fácil execução. No meio de uma corda de 10 metros de comprimento, arma-se um anel que fica colocado na base do pescoço, onde as extremidades desta corda se cruzam sobre o pescoço, passam de volta por dentro do anel e dirigem-se para trás, contornando as quartelas posteriores. Ai, estas pontas são trazidas e puxadas diretamente para trás e/ou passam novamente pelo anel do pescoço e são direcionadas para trás. Nesta manobra, o animal vem ao solo (FEITOSA, 2014; MARTINS, 2019).

\section{Ovinos e caprinos}

Na contenção de ovinos e caprinos, deve-se procurar capturar o membro posterior, procurando puxar este para trás e para cima, procurando ter o máximo de cuidado para não ocasionar luxações e/ou fraturar o animal. Também pode-se procurar montar sobre o animal e imobilizalo, segurando pelos chifres. É possível procurar conter o animal segurando este pelo seu "colar" ou até mesmo pela "barba", e se for o caso, também pelas orelhas (FEITOSA, 2014; MARTINS, 2019).

Uma vez contido o animal, um auxiliar poderá colocar-se lateralmente ao animal e procurar segurar o seu flanco, e com a outra mão, segurar a mandíbula, mantendo-o assim, contido. Nesta situação, se for necessário, o ajudante poderá proceder com a derrubada do animal. Em última instancia, sendo o animal muito arredio, pode-se proceder a contenção colocando o animal em decúbito lateral, e utilizando o joelho, proceda em prenda cuidadosamente o pescoço do animal, ao mesmo tempo que segura os membros posteriores do animal com uma das mãos (FEITOSA, 2014; MARTINS, 2019).

\section{Contenção de suínos}

Para os suínos, recomenda-se utilizar o "cachimbo com haste de ferro" para os animais alojados em baia. Nas gaiolas de gestação e de maternidade, deve-se utilizar o "cachimbo de corda", por ser este mais flexível, possibilitando a utilização da ferragem da gaiola como apoio, 
contribuindo com a obtenção de uma melhor posição do animal para seu manejo (MARTINS, 2019).

\section{Animais silvestres}

Para a contenção de animais silvestres, por serem estes animais que não estão acostumados a serem manuseados por humanos, deve-se ter mais cuidado para evitar acidentes. Assim podese utilizar, na lida com estes animais:

Ganchos:

É utilizado para conter serpentes, contendo a cabeça dela sobre uma superfície sólida. Também, para inibir um ataque, este gancho serve para suspender o animal, fazendo com que este tenha pouca possibilidade de desferir um ataque contra o operador. $\mathrm{O}$ gancho é composto de um cabo de material resistente, e possui uma ponta em "L", feito em metal (MARTINS, 2019; SILVA, 2007; SILVA et al., 2012).

Luva de raspa de couro:

Utilizadas para proteção das mãos na aproximação e contenção direta de um animal. Também pode ser utilizado em associação a outro equipamento de contenção física (MARTINS, 2019; SILVA, 2007, SILVA et al., 2012).

\section{Puçá:}

Utilizado para a contenção de muitas espécies de animais, como as aves, mamíferos, e répteis, são manuseados, principalmente, para animais com pouca agressividade e que apresentam dificuldades de serem capturados por aproximação. Sua confecção envolve um cabo de material resistente, e possuindo em uma extremidade uma rede de cordas ou saco de pano, preso a um aro de metal. Esta rede pode possuir diferentes tamanhos (MARTINS, 2019; SILVA, 2007; SILVA et al., 2012).

Rede:

Confeccionadas em cordas de fibras naturais ou sintéticas, são empregadas na contenção e captura de várias espécies de aves e mamíferos. Redes de malha fina, em geral de cor preta, são utilizadas como instrumento de captura de aves e morcegos, sendo este um dos principais métodos empregados (MARTINS, 2019; SILVA, 2007; SILVA et al., 2012). 
Cambão:

Os cambões são equipamentos utilizados para contenção de várias espécies, principalmente mamíferos. Este é composto de um cabo de material resistente, que serve de guia para um laço confeccionado com tira de couro ou corda. Estes são utilizados laçando a região cervical e um dos membros torácicos, ou apenas a região cervical, do animal que está sendo manipulado (MARTINS, 2019; SILVA, 2007; SILVA et al., 2012).

Jaula e caixa de contenção:

Estes podem ser adquiridas em madeira ou metal. Devem ter um mecanismo de engrenagens e trilhos para possibilitar a contenção do animal. Facilita a manipulação do animal, contribuindo para uma ação clínica de prevenção ou curativo, além de facilitar outros procedimentos mais complexos (MARTINS, 2019; SILVA, 2007; SILVA 2012).

Tubos:

Este é utilizado no auxiliar na contenção de animais como as aves, répteis e alguns mamíferos. Com este realiza-se a manipulação de serpentes, facilita o anilhamento de aves e contribui para um procedimento rápido em mamíferos de pequeno e médio porte. Estes tubos, que devem ser de materiais adequados, podem ser de diâmetros diversos mas de fácil higienização. (MARTINS, 2019; SILVA, 2007; SILVA et al., 2012).

\section{CONCLUSÃO}

Restringir da maneira eficiente o animal para manipulações é necessário pois o paciente ao ser manipulado poderá se defender com mordeduras, coices, chifradas e/ou unhadas. Nesta realidade é que se torna importante que o animal esteja adequadamente contido, e esta revisão apresenta, de forma geral, uma melhor compreensão destas técnicas que proporcionam uma ação com os animais de melhor qualidade e segurança.

\section{REFERÊNCIAS}

ANDRADE, A.; CORREIA PINTO, S.; OLIVEIRA, R.S. (Org.). Animais de laboratório: criação e experimentação. Rio de Janeiro: Editora FIOCRUZ, 2002.

BARDIN, L. Análise de conteúdo. Tradução: Luís Antero Reto e Augusto Pinheiro. Lisboa: Edições 70, 1977. Título original: L' Analyse de Contenu. 
DIAS, T.C.L.; SANTOS, J.L.C.; CORDENUZZI, O.C.P.; PROCHNOW, A.G. Auditoria em enfermagem: revisão sistemática da literatura. Revista Brasileira de Enfermagem, Brasília, v. 64, n. 5, p. 931-941, 2011.

FEITOSA, F.L.F. Contenção Física dos Animais Domésticos. In: FEITOSA, F.L.F. Semiologia Veterinária: A Arte do Diagnóstico. 3. ed. São Paulo: Roca, 2014. p. 29-45.

GIL, A.C. Métodos e técnicas de pesquisa social. 6. ed. São Paulo: Atlas, 2011.

MARTINS, D. Métodos de contenção em diferentes espécies animais. Agronomia, cursos. Aula 1. 2019. Disponível em: https://agronomiaconcursos.com.br/wpcontent/uploads/2019/04/Aula-1-conten\%C3\%A7ao-animal-16042019.pdf. Acesso em: 09 jan. 2020.

SENAR. Bovinocultura: contenção de bovinos. Serviço Nacional de Aprendizagem Rural. 1. ed. (Coleção SENAR, 164). Brasília: SENAR, 2017. 91p.

SILVA, L.A.F.; EURIDES, D.; RODRIGUES, D.F.; SOUZA, L.A.; MENDES, F.F. Contenção física de animais domésticos, selvagens e de laboratório. Goiânia: Kelps, 2012.

SILVA, L.C.S. Contenção e captura de animais selvagens. Centro Científico Conhecer, 2007. Disponível em: http://www.conhecer.org.br/. Acesso em 26 out. 2020. 